مقومات الجذب السياحي في مدينة الطائف

مقومات الجذب السياحي في مدينة الطائف

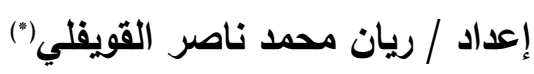

باحث بقسم الجغرافيا ونظم المعلومات الجغرافية، كلية الآداب والعلوم الإنسانية

جامعة الملك عبد العزيز.

يهدف البحث إلى التعرف على عناصر الجذب السياحي بمدينة الطائف، والتعرف

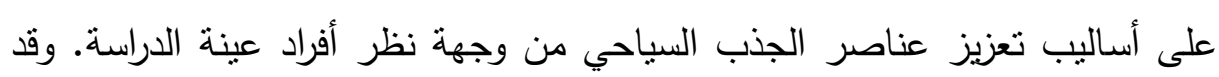

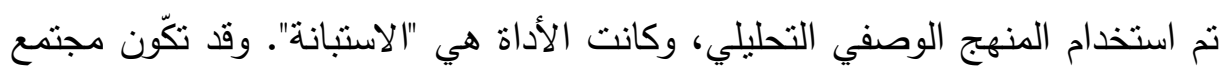

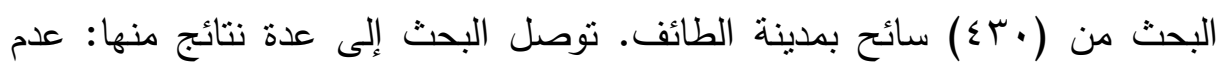

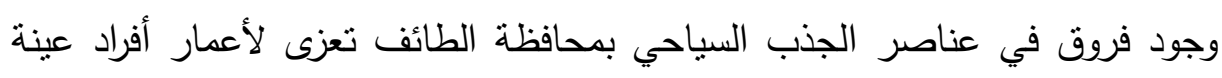

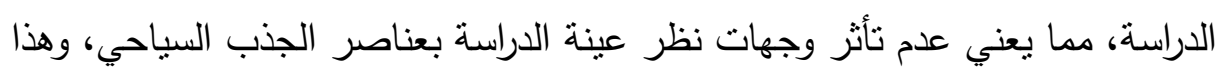

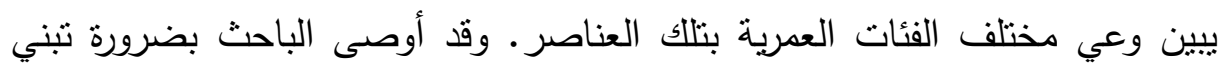

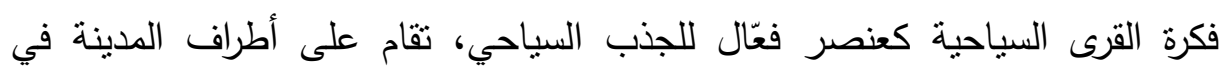

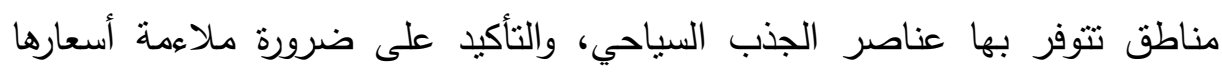

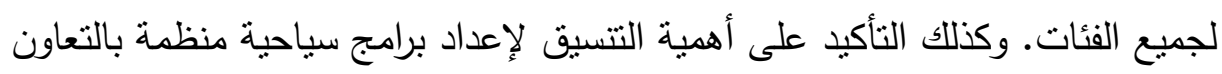

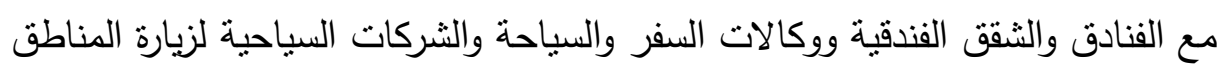

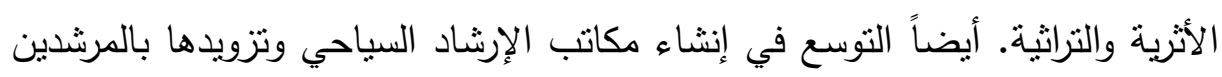
السياحيين لضمان زيادة الوعي السياحي للسكان في المنطقة.

\title{
أولا: الاقدهمة:
}

بدأت السياحة منذ ظهور الإنسان على وجه الأرض، وكانت بسيطة وبدائية في

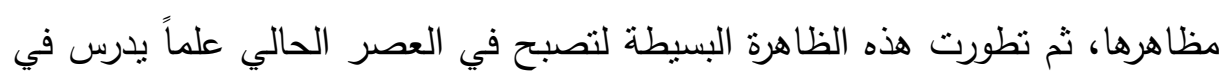

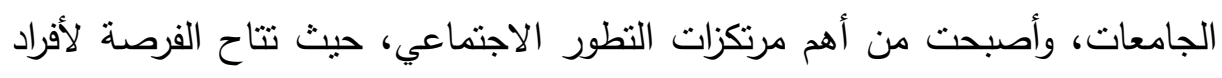

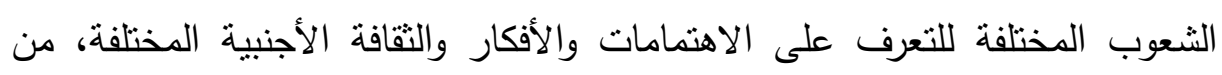

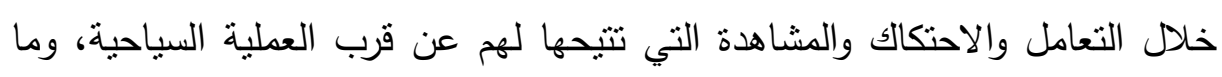

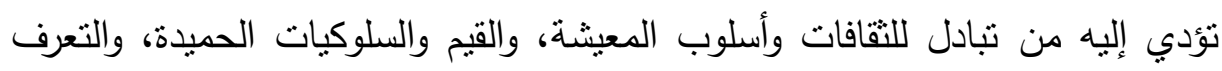


د / ريان محمد ناصر القويفلي

على ثقافات وحضارات وتقاليد جديدة، كما تؤدي إلى زبادة إنتاجية الأفراد، وزيادة ترابط العلاقات الاجتماعية، والوعي الثقافي والاجتماعي.

وتعد مدينة الطائف واحدة من مناطق الجذب السياحي الرئيسية في المملكة العربية السعودية؛ يرجع ذلك إلى طقسها اللطيف في الصيف، ولاحتوائها على النباتات الجميلة في موسم الربيع. كما أنها المدينة التي تقدم الثقافة التاريخية الغنية، وبطلق

عليها العاصمة الصيفية للمملكة العربية السعودية. وحول مفهوم السياحة فقد تتاول الباحثون تعريفها من عدة جوانب، فمنهم من

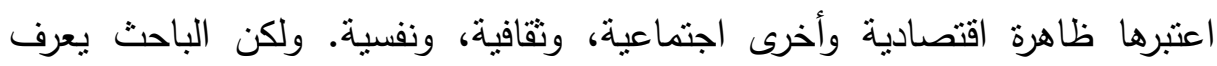
السياحة بأنها نشاط إنساني يتعلق بالحركة والتنقل، يقوم به فرد أو مجموعة الأفراد

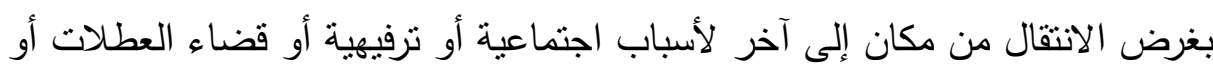

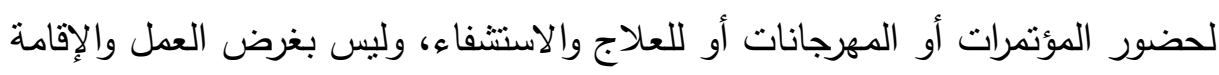
الدائمة والذي ينتهي بالعودة إلى منطقة الانطلاق، فالسياحة مرتبطة بمكانين نقطة الانطلاق (المصدر) ونقطة الاستقبال (الهدف) بانه كما يعرف الباحث السائح بأنه كل شخص ينتقل خارج مكان إقامته المعتادة وذلك

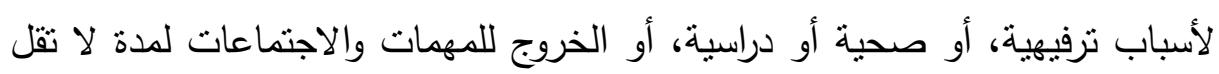

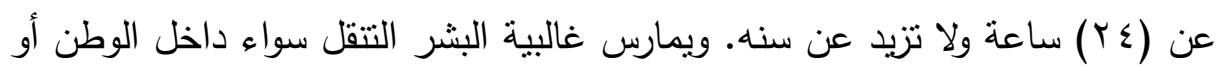
خارجه، فمنهم من ينتقل للحصول على عمل ومنهم من يهاجر، وآخرون لزيارة الأقارب، وآخرون لأغراض سياسية.

وتتعدد أنواع السياحة تبعا للدوافع والرغبات والاحتباجات المختلفة، فهناك السياحة

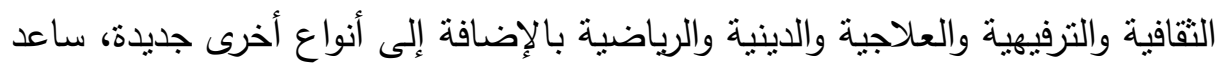
على ظهورها وانتشارها التقدم والتطور العلمي والسياسي والاقتصادي والاجتماعي، وما

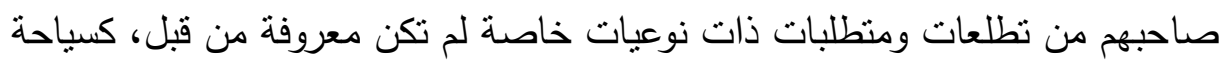

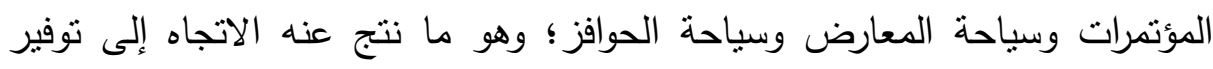
خدمات وتسهيلات وتجهيزات وعناصر جذب مختلفة، ويمكن تصنف النشاط السياحي وهي ولهي

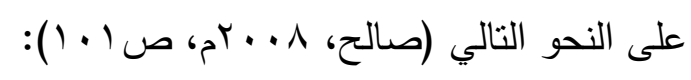
مجلة بحوث كلية الآداب 1007 
مقومات الجذب السياحي في مدينة الطائف

• طبقا لعدد الأشخاص المسافرين: ولها صور منها: سياحة فردية- جماعية.

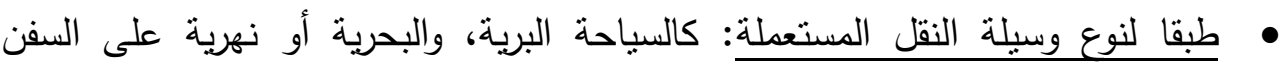

$$
\text { والبواخر، وجوية على الطائرات. }
$$

طبقا للسن: وتثمل سياحة المرحلة التعليمية والثركات السياحية، والجمعيات الخيرية،

$$
\text { وتعلم السباحة أو الحاسوب. }
$$

هبقا لمعيار مستوى الإنفاق: كسياحة محدودي الدخل، وسياحة الأغنياء.

• طبقا للمناطق الجغرافية: وتقسم إلى سياحة داخلية، وإقليمية، وخارجية. طبقا للجنسية: تتضمن جميع الأجانب ما عدا مواطني البلدا.

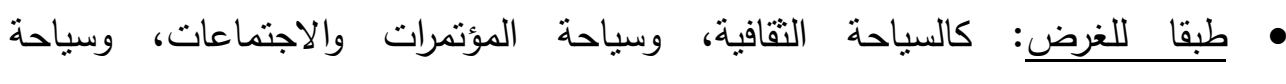
المهرجانات.

موقع منطقة الدراسة: - مات

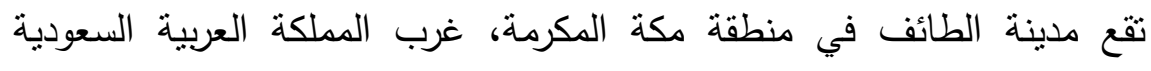

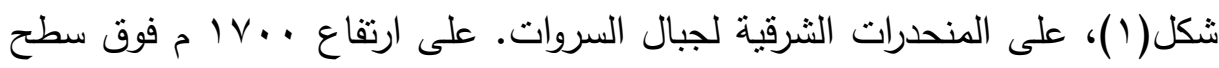

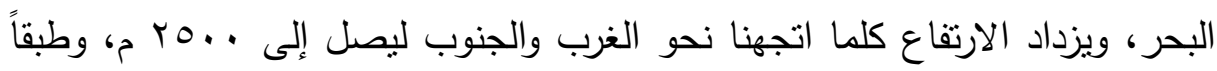

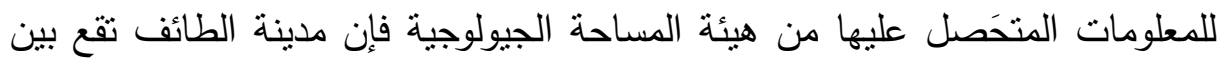

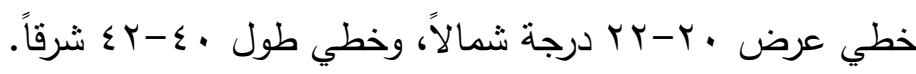




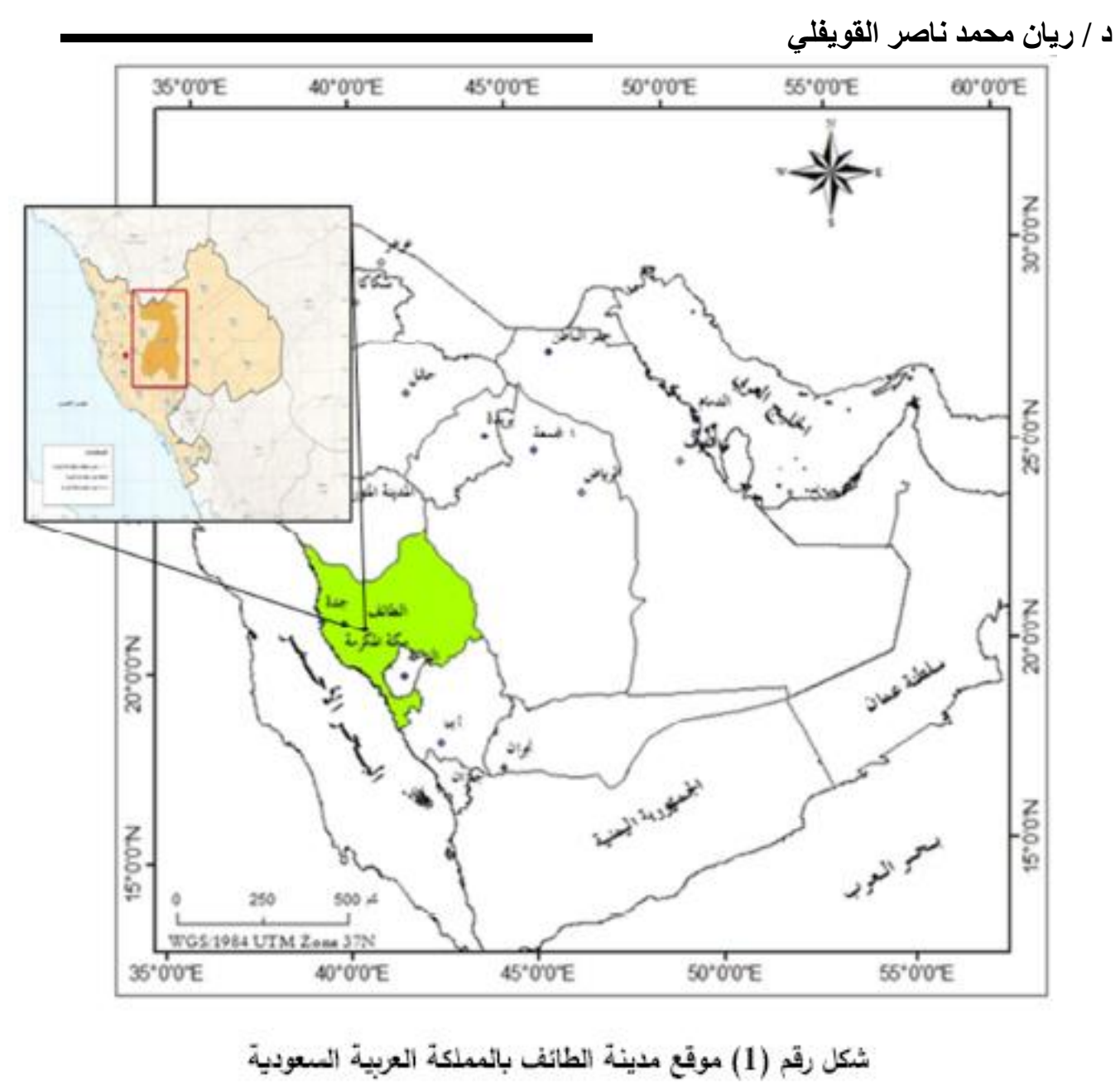

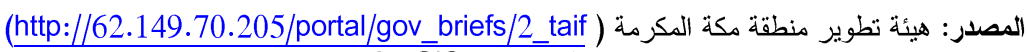
اعتمادا على برمجية ArcGIS

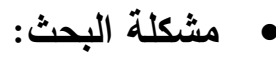

يعد نوفُّر المقومات السياحية الركيزة الأساسية التي تعتمد عليها أبي مدينة أو دولة

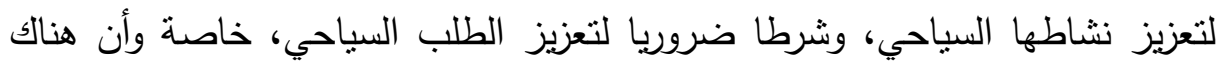
صعوبة في استقطاب السياح، وتعذر ضمان جذبهم سنويا؛ بسبب كثرة المغريات السياحية في المناطق المختلفة، لذا نأتي هذه الدراسة لتتناول مقومات الجذب السباحي

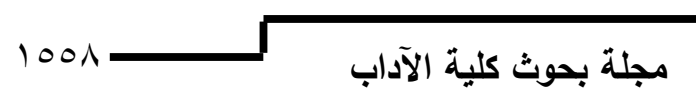


مقومات الجذب السياحي في مدينة الطائف

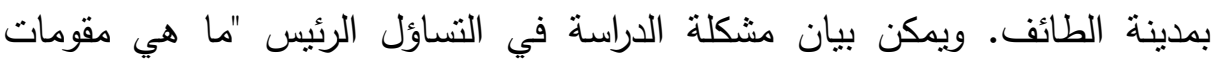

الجذب السياحي في مدينة الطائف؟"

هدف الدراسة:

التعرف على عناصر الجذب السياحي بمدينة الطائف من وجهة نظر أفراد عينة

• أهمية البحث في روئة السياحة في المملكة العربية السعودية:

تسعى المملكة العربية السعودية وهي مهد الإسلام، ومهبط الوحي، ومنبع العروبة، إلى تتمية سياحية ذات قيمة مميزة، ومنافع اجتماعية، واقتصادية، وثقافية، وبيئية، انطلاقا من قيمها الإسلامية، وأصالة تراثها العريق، وسمو ما تتمتع به المملكة من قيم

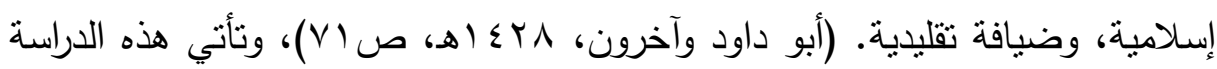
مساهمةً علمية في تقديم نموذج يمكن الاستفادة منه من قِبَّل المطورين وذي المسؤولية بهذا الثأن.

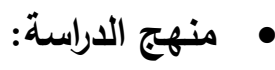

في إطار هدف الدراسة سوف يعتمد الباحث على المنهج الوصفي التحليلي، حيث تبرز أهمية الأسلوب الوصفي التحليلي في كونه الأسلوب المناسب الذي يمكّن من دراسة بعض الموضوعات الإنسانية؛ لاعتماده على دراسة الواقع، ودراسة الظاهرة كما

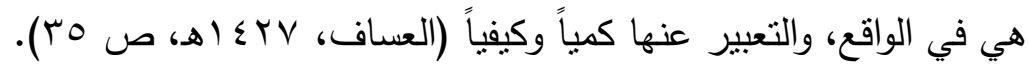

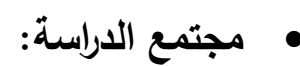
يمثل مجتمع الدراسة جميع السائحين بمدينة الطائف خلال فترة موسم صيف عام

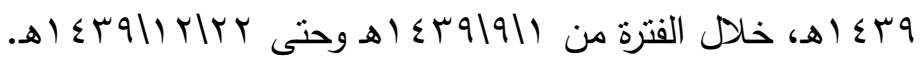
• - مينة الدراسة:

"الأصل في البحوث العلمية أن تجرى على جميع أفراد مجتمع البحث؛ لأن ذلك أدعى لصدق النتائج، ولكن يلجأ الباحث إلى اختيار عينة منهم إذا تعذر ذلك بسبب

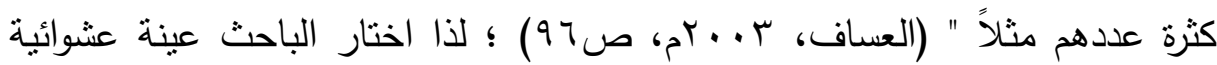
باستخدام جدول تحديد حجم العينة ونظراً لكون مجتمع الدراسة كبير فسوف يستخدم 
د / ريان محمد ناصر القويقلي

الباحث أسلوب العينة العشوائية لعدد ( . .0) سائح خلال الفترة المعنية بالدراسة، وقد بلغ إجمالي عينة الدراسة القابلة للقياس والتحليل ( • ع ع) سائح.

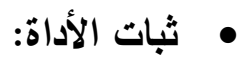

لقياس مدي ثبات أداة الدراسة (الاستبيان) استخدم الباحث (معادلة ألفا كرونباخ (Alpha Cronbacha

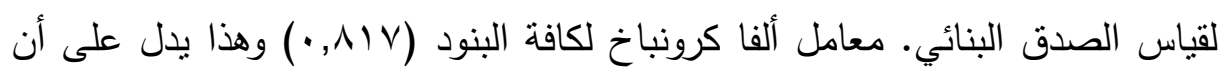
محاور الدراسة والاستبانة تتمتع بدرجة عالية من الثبات، ويمكن الاعتماد عليها في التطبيق المبداني للاراسة. الدراسات السابقة:

تتاول العديد من الباحثين لما يتعلق بالجغرافيا السياحية، منها على سبيل المثال

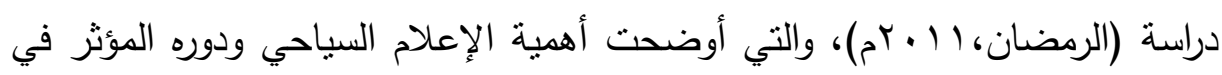
السياحة الداخلية، والكثف عن مواطن الضعف في الإعلام السياحي في المملكة

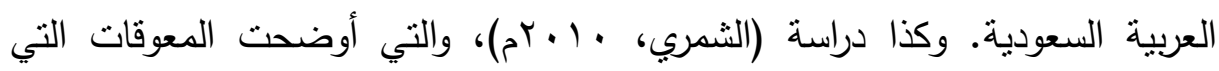

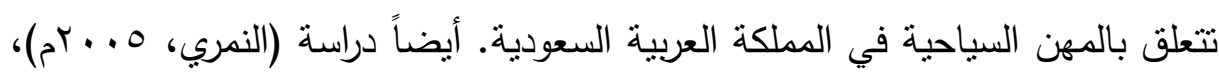
والتي بينت بعض الأسس العلمية، والقواعد الثرعية، والضوابط الاجتماعية، والمبادئ الاقتصادية التي تجعل من تصرفات السياح والمتعاملين مع البيئة والعاملين فيها مقبولة دينياً، واجتماعياً واقتصادياً، وبيئياً.

\section{ثانيا: الاقومات الطبيعية والثزوبية بمدينة الطائف:}

• طبوغرافية مدينة الطائف:

يعتبر موقع مدينة الطائف نقطة التلاحم بين التضاريس الجبلية لسلسلة جبال السروات وبين نهايات الأرض المنبسطة لهضبة نجد، حيث تقع المدينة في سفح شبه مستوي من سفوح جبال السروات على السهول الثرقية لوادي وج، وتتميز تضاريسها بالمرتفعات الجبلية في الجنوب والغرب وبالسهول المنبسطة في الثمال الشرقي، كما تتميز المرتفعات الجبلية بوعورتها وشدة انحدارها في بعض المواقع. ويخترق مدينة

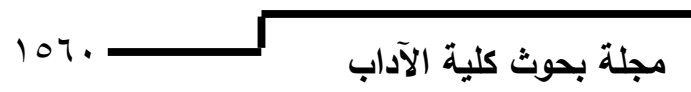


مقومات الجذب السياحي في مدينة الطائف

الطائف بعض الأودية الحاضنة للعديد من المزارع، حيث تغطى هذه الجبال بمساحات خضراء ومناطق ذات تكوينات صخرية مختلفة تشكّل مناظر طبيعية خلابة ومورد

يمكن توظيفه في مجال السياحة الطبيعية.

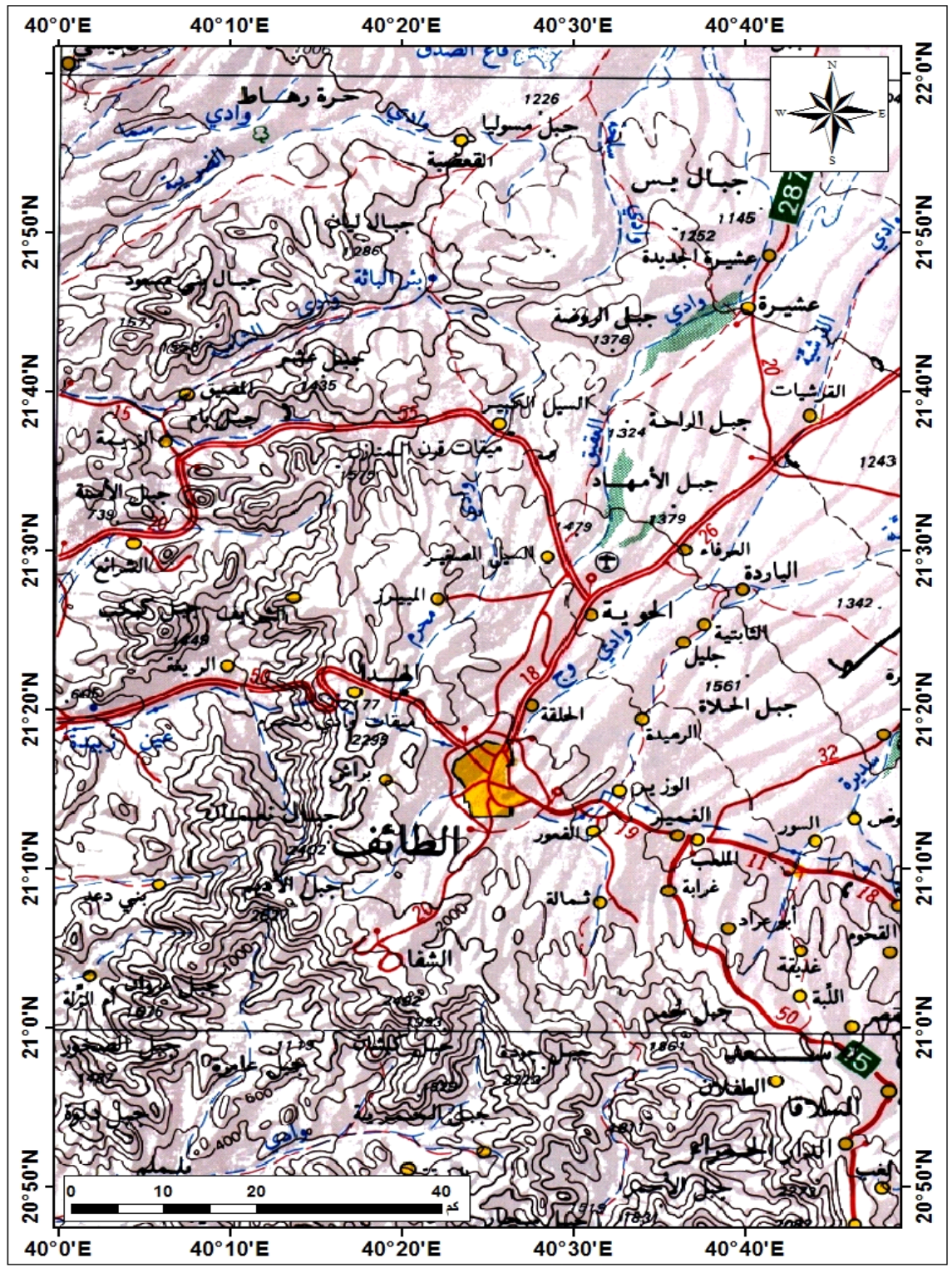

شكل رقم (ץ) خريطة كنتورية لمدينة الطائف

المصدر: Arc/http://www.athagafy.com/maps واستتادا إلى برمجية Arc GIS10 
يؤثر المناخ في العملية السياحية، عند شريحة كبيرة من المجتمع البشري، لاسيما

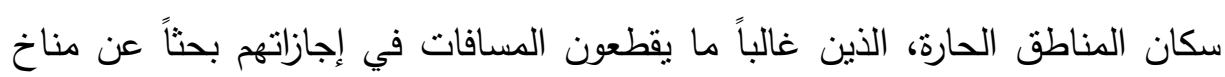

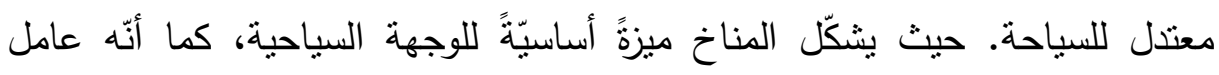

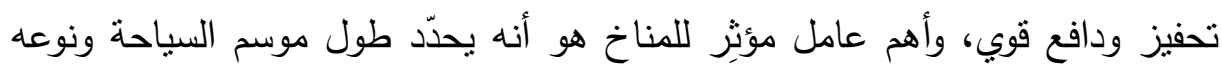
في مدينة الطائف.

بلغ معدل الهطول السنوي في محطة رقم TA206 حوالي 170.VV ملم، وكان أكبر هطول يومي سجلته المحطة في يوم ^ من شهر يناير عام ا ... م م، كما أن هذا

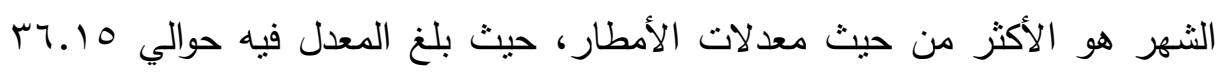
ملم خلال فترة التسجيل. ويعد فصل الربيع أكثر الفصول المطيرة، بسبب نأثر المنطقة بالرياح في هذا الفصل. وتهبّ الرياح غالباً من الجهة الجنوبية الغربية، والثمالية

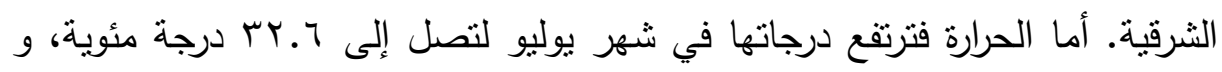

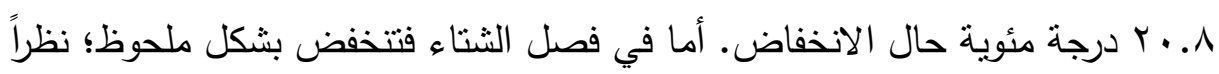
لارتفاعها الثاهت عن سطح البحر. وفيما يتعلق بالرطوبة النسبية فقد سجلت ارتفاعاً بلغ متوسطها

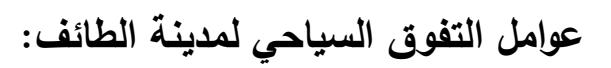

تهدف السياحة إلى استثمار الموارد الطبيعية والبشرية المتاحة في المنطقة أو الدولة، كالثواطئ الرملية، أو المناخ المعتدل، أو المناطق الجبلية، أو الغطاءات الجليدية، أو الأماكن الدينية، والتاريخية، والأثرية، وهي بذلك لا تختلف على التى الأنشطة الاقتصادية الأخرى التي تسعى إلى استغلال الموارد الطبيعية المتاحة، كالموارد المعدنية والغابات.

وقد لعبت مدينة الطائف منذ القدم دوراً مهماً كمحطة مهمة على طرق التجارة والحج القادمة من شرق الجزيرة العربية، ومركز خدمات للتجمعات الزراعية حولها، وقد تبلورت أهمية موقعها من خلال شبكة الطرق السريعة التي تربطها بالمراكز العمرانية 
مقومات الجذب السياحي في مدينة الطائف

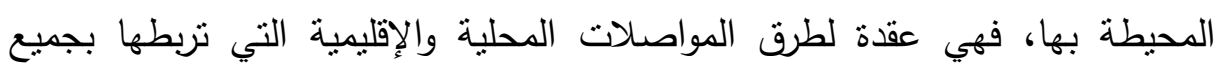

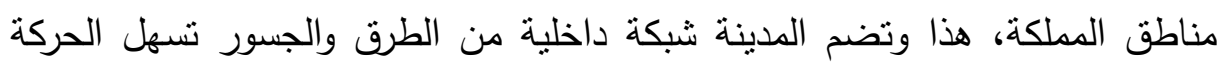

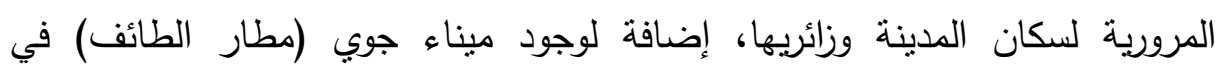

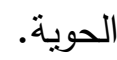

\section{ثالثا: هؤشرات وخصائص المركة السياهية بمدينة الطانف:}

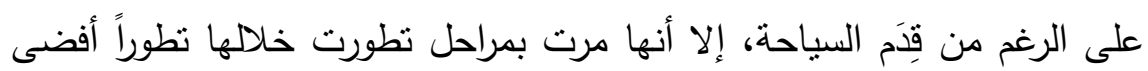

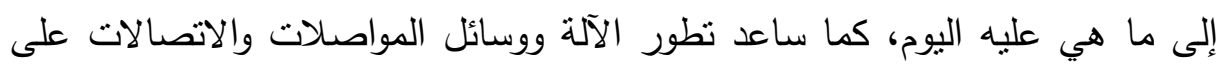

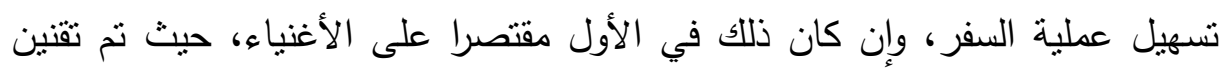

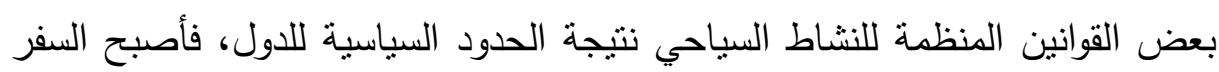

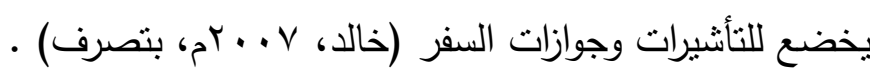
• مؤثرات العركة السياحية بمدينة الطائف:

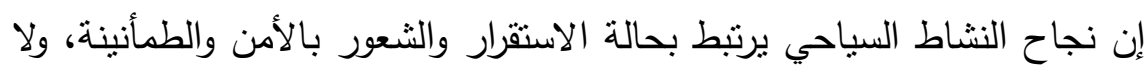

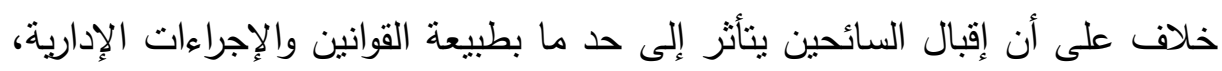

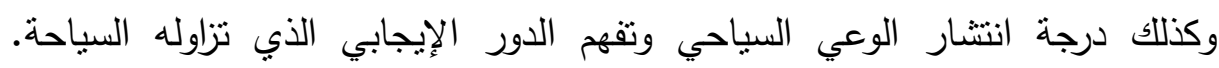

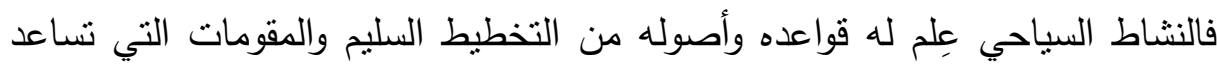

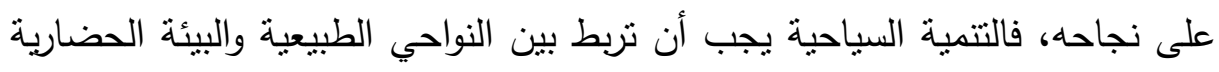

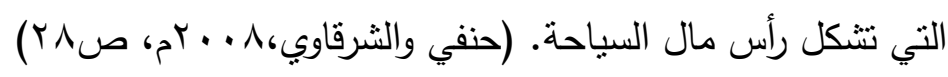

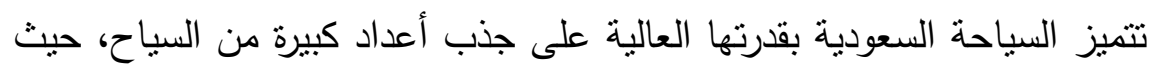

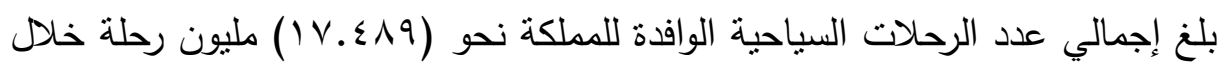

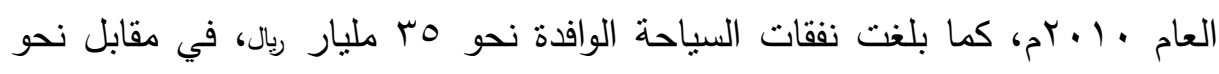

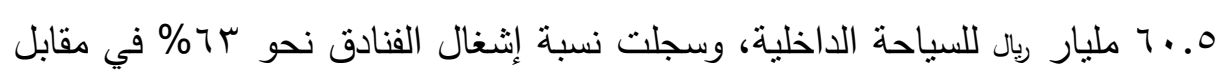

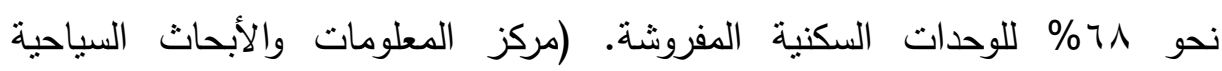

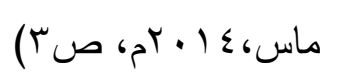

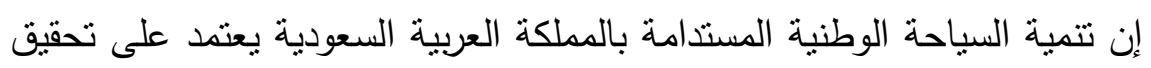
الجذب السياحي للوجهات السياحية في الملكة، إضافة إلى قيام الهيئة العامة للسياحة لئنة 
بتطوير السياحة بالتعاون مع شركاءها في القطاعين العام والخاص، في سبيل تحقيق اهتمام المملكة بالسياحة والتنمية فيها على المستوى العالمي. خصائص الحركة السياحية بمدينة الطائف: تم التحليل من خلال الإجابة عن تساؤلات الدراسة في الاستبانة، ومن ثَ حساب التكرارات والنسب المئوية والمتوسطات الحسابية والانحرافات المعيارية والرتب لاستجابات أفراد الدراسة على أسئلة الاستبانة، علماً أن الاستبيان تم توزيعه على أفراد عينة الدراسة من السياح والمتنزهين المتواجدين بمدينة الطائف لصيف عام 1 1 • rم،

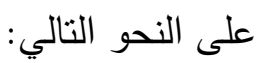
أولاً: يتبين من الجدول (1) التالي:

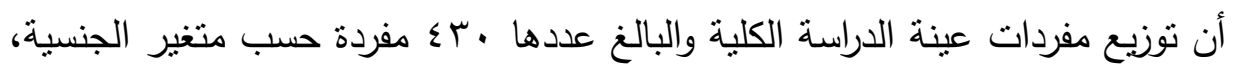

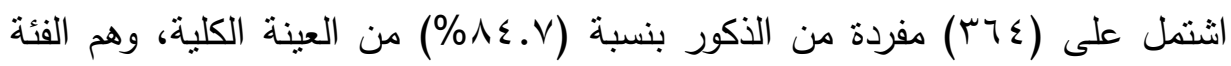

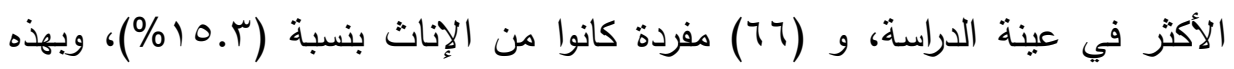
النتيجة نستطيع القول أن الذكور يشكلون غالبية السياح في محافظة الطائف.

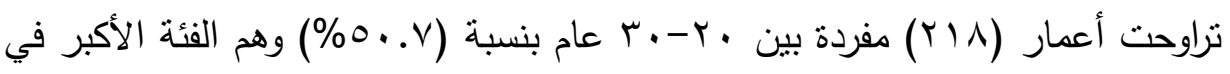

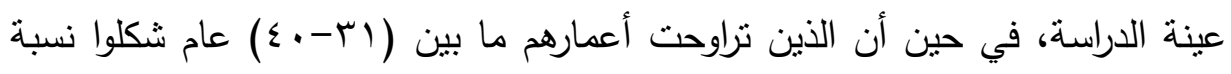

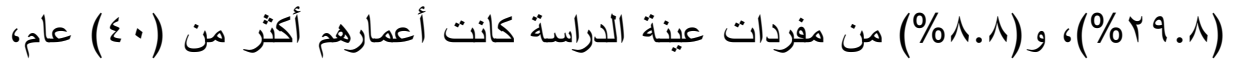
وتشير هذه النتيجة إلى أن أغلب السياح كانوا من فئة الثباب، مما بعني أن فئة الثباب هم من الفئات الأكثر اهتماماً بالسياحة مقارنة مع بقية الفئات العمرية.

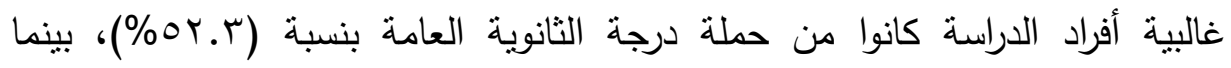

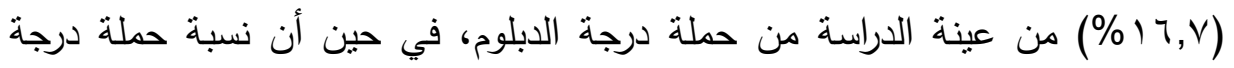

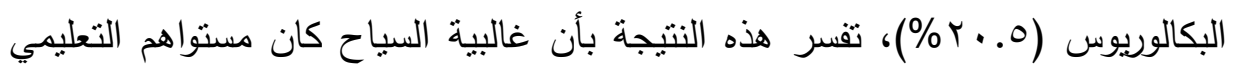
جيد، وهذا يوحي بأن لديهم نسبة من الوعي الثقافي بأهمية ودور السياحة لدى المواطن السعودي. نسبة أفراد الدراسة من غير المتزوجين (؟ (7 \%\%)، ونتير هذه النتيجة إلى تتوع السياح على محافظة الطائف ما بين المنزوجين وغير المنزوجين. 
مقومات الجذب السياحي في مدينة الطائف

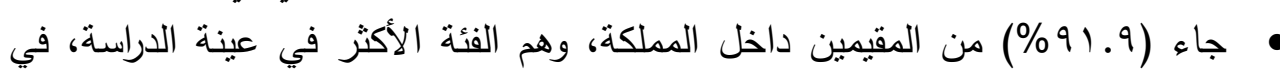

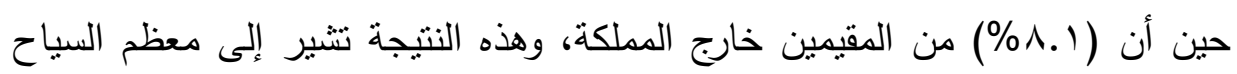
من الذين يتوافدون من داخل المملكة. (9. . ؛ \%) يتخدمون السيارات الخاصة للوصول لمحافظة الطائف، وهم الفئة الأكبر

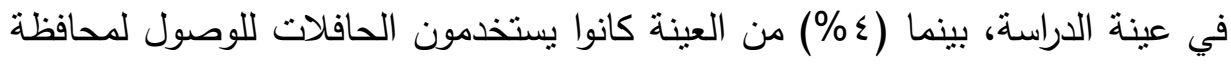
الطائف.

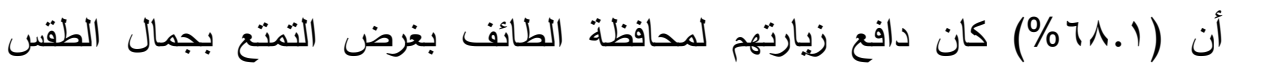

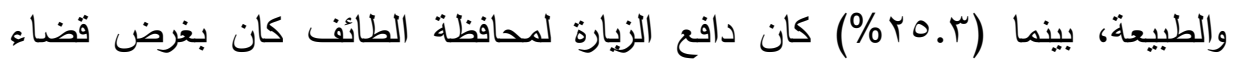
الإجازة، في حين أن (^.^\%) كان الدافع هو التعرف على الأماكن الأثرية والتاريخية،

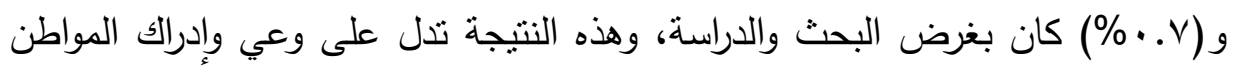
السعودي بجمال الطقس والطبيعة التي تتمتع بها محافظة الطائف دون غيرها من

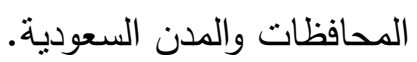
يُقصد بمحور المشاكل على الطريق: هو وجود مشاكل قد تواجه السياح على الطريق،

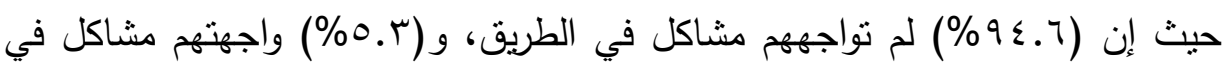
الطريق إلى محافظة الطائف.

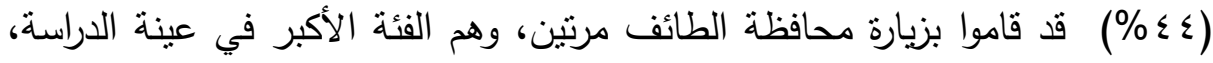

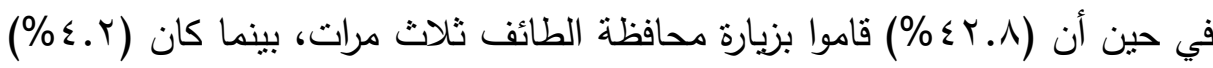
من العينة قد قاموا بزيارة محافظة الطائف مرة واحدة.

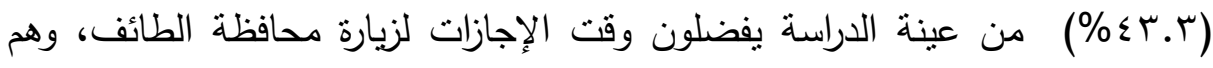

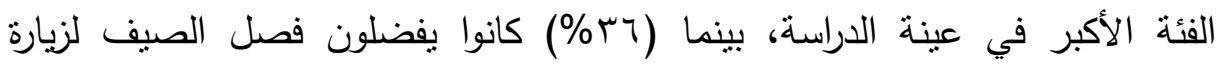

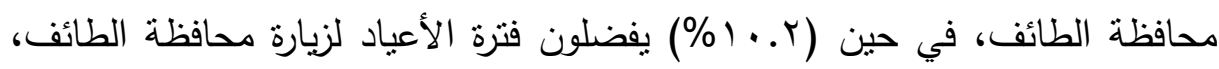

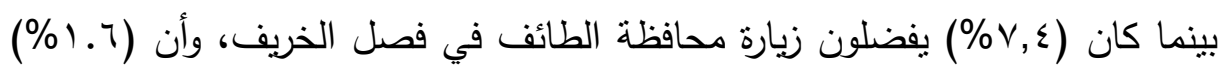

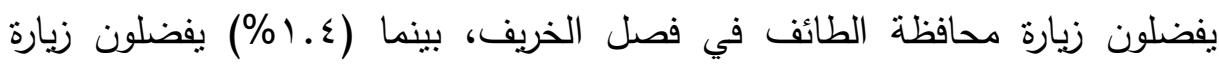
محافظة الطائف في فصل الثتاء. 
د / ريان محمد ناصر القويفلي

جدول ( ) : نتائج إجابات أسئلة الاستبانة التي وُزِعت على عينة الدراسة بمدينة الطائف

\begin{tabular}{|c|c|c|c|}
\hline النسبة (\%) & التكرار & الوصف & سوال الاستبانة \\
\hline $\begin{array}{l}9 . . v \\
9 . r\end{array}$ & $\begin{array}{c}r q . \\
\varepsilon .\end{array}$ & غير سعودي & الجنسية \\
\hline$\wedge \varepsilon . \vee$ & M & 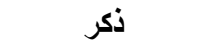 & \multirow{2}{*}{ الجنس } \\
\hline $10 . r$ & 79 & أنثى & \\
\hline $\begin{array}{l}1 \cdots v \\
0 . v\end{array}$ & $\begin{array}{l}\leq 4 \\
Y 11\end{array}$ & 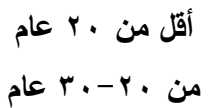 & \multirow{3}{*}{ العمر } \\
\hline rq.1 & IrA & من اس-. . عام & \\
\hline$\Lambda . \wedge$ & $\mu \wedge$ & أكثر من · ع عام & \\
\hline OY.r & rro & ثانوية & \multirow{5}{*}{ الارجة العلمية } \\
\hline 17.8 & Vr & دبلوم & \\
\hline$r . .0$ & $\wedge \wedge$ & بكالوريوس & \\
\hline 9.0 & $\leq 1$ & ماجستير & \\
\hline$\cdot .9$ & $\varepsilon$ & دكتوراه & \\
\hline
\end{tabular}

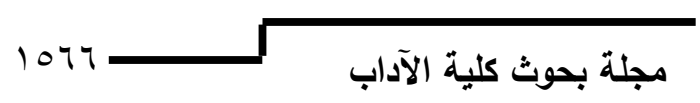


مقومات الجذب السياحي في مدينة الطائف

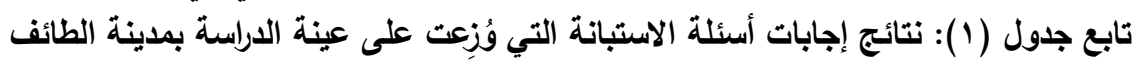

\begin{tabular}{|c|c|c|c|}
\hline النسبة & التكرار & الوصف & سؤال الاستبانة \\
\hline$\varepsilon 7 . r$ & & & الحالة الاحتماعية \\
\hline or.v & 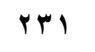 & متزوج & \\
\hline 91.9 & rq० & داخل المملكة & \multirow{2}{*}{ مكان الإقامة } \\
\hline$\wedge .1$ & ro & خارج المملكة & \\
\hline$\varepsilon$ & iv & حافلة & \multirow{4}{*}{ وسيلة النقل } \\
\hline$\varepsilon \cdot .9$ & 187 & سيارة خاصة & \\
\hline$r \cdot r$ & $\Lambda \vee$ & سيارة أجرة & \\
\hline$r \varepsilon .9$ & 10. & طائرة & \\
\hline 0.1 & ro & التعرف على الأثرية & \multirow{4}{*}{ دوافع الزيارة } \\
\hline 71.1 & rq & التمتع بجمال الطقس & \\
\hline ro.r & 1.9 & قضاء الإجازة & \\
\hline$\because V$ & $r$ & للبحث والدراسة & \\
\hline $0 . \varepsilon$ & rr & نعم & \multirow{2}{*}{ المشاكل في الطريق } \\
\hline $9 \varepsilon .9$ & $\varepsilon \cdot V$ & لا & \\
\hline$\varepsilon . r$ & 11 & مرة & \multirow{4}{*}{ عدد مرات زيارة محافظة } \\
\hline$\leqslant \leqslant$ & 119 & مرتين & \\
\hline$\varepsilon Y . \wedge$ & $1 \Lambda \varepsilon$ & ثلاث مرات & \\
\hline 9.1 & $r q$ & أكثر من ثلاث مرات & \\
\hline $1 . \varepsilon$ & 7 & فصل الشتاء & \multirow{6}{*}{ الأوقات المفضلة } \\
\hline rq & 100 & فصل الصيف & \\
\hline 1.7 & $v$ & فصل الخريف & \\
\hline$V . \varepsilon$ & rr & فصل الربيع & \\
\hline$\ddot{r}$ & $\varepsilon \varepsilon$ & فترة الأعياد & \\
\hline$\varepsilon r$. & $1 \wedge 7$ & وقت الإجازات & \\
\hline
\end{tabular}

المصدر : من عمل الطالب اعتمادا على تفريغ استمارة استبيان 
د / ريان محمد ناصر القويفلي

\section{رابعا :الأهمية النسبية لعناصر البذب العيدياهي بمدينة الطانف:}

بعد التطور الذي حدث في مجال السياحة أصبحت السياحة قطاعات اقتصاديا رئيسا يعمل على إيراد الكثير من العملات الصعبة، وزيادة الاستثمار الأجنبي في البلد السياحي، وأيضا زيادة فرص العمل للكثير من الأيدي العاملة. ويتضح من الجدول رقم (Y) أن محور عناصر الجذب السياحي يتضمن

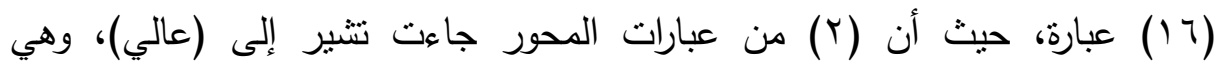

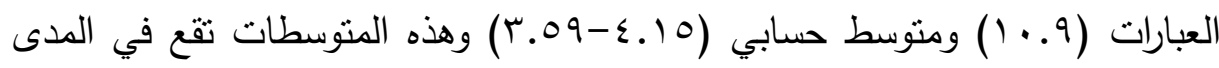

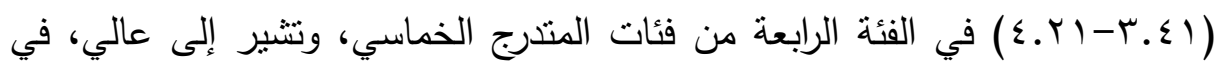

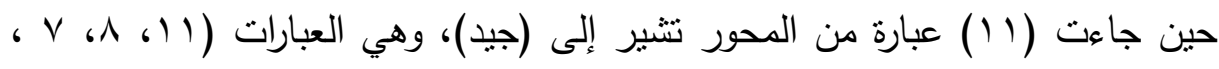

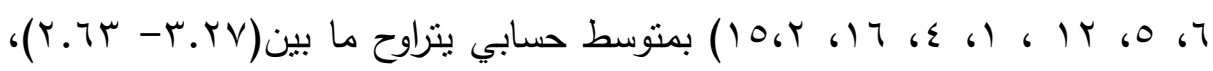
وهذا المنوسط يقع في المدى (اT.Y- إ.ب) في الفئة الثالثة من فئات المتدرج الخماسي والتي تشير إلى موافق، و(r) عبارات من عبارات المحور جاءت تشير إلى

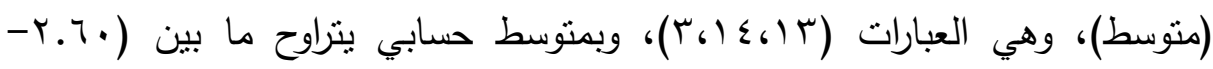

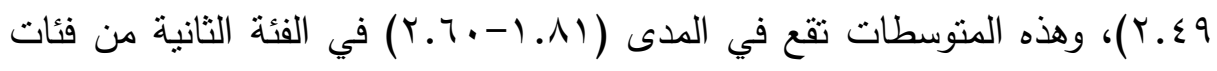
المتدرج الخماسي وتتير إلى متوسط.

كما يتضح من المتوسط العام وهو (ب.9.4) أن متوسط عبارات محور عناصر الجذب السياحي، جاءت نتير إلى درجة ممارسة (جيد) من قبل وجهة نظر أفراد عينة الدراسة، وتقسر تلك النتيجة أن عناصر الجذب السياحي بمحافظة الطائف كانت على إلى درجة جيدة من حيث الأمن والاستقرار ووسائل الترفيه، والأنشطة السياحية وكذلك به خدمات المركز الصحي، وقد جاءت استجابات أفراد الدراسة على عبارات المحور حسب منتوسطات الموافقة عليها على النحو التالي: جاءت العبارة رقم (• (1) وهي" الأمن والاستقرار " بالمرنبة الأولى من حيث موافقة أفراد الدراسة عليها بدرجة عالية بمتوسط (10,؛)، وتتشير هذه النتيجة إلى أن ما نسبته 
مقومات الجذب السياحي في مدينة الطائف

(ץ^\%) من أفراد عينة الدراسة موافقين بدرجة عالية، على وجود الأمن والاستقرار

داخل محافظة الطائف، إذ يعتبر هذا من أهم عناصر الجذب السياحي.

جاءت العبارة رقم (9) وهي" وسائل الترفيه" بالمرتبة الثانية من حيث موافقة أفراد الدراسة عليها بدرجة عالية بمتوسط (ب9.09)، وتتثير هذه النتيجة إلى أن ما نسبته (\% من السياح في مجتمع الدراسة موافقين بدرجة عالية على دور وسائل التزفيه في الجذب السياحي، حيث تعرف السياحة بأنها نشاط السفر بهدف الترفيه. جاءت العبارة رقم (1) (1) وهي" الأنشطة السياحية " بالمرتبة الثالثة من حيث موافقة أفراد

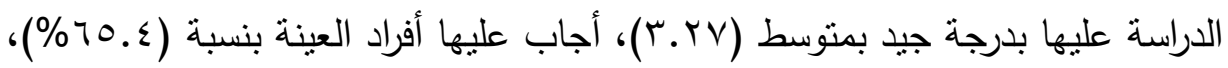
وتثبير تلك النتيجة على أهمية تفعيل الأنشطة السياحية المتمتلة في سياحة المؤتمرات وسياحة المعارض وسياحة الحوافز، وهو ما نتج عنه الاتجاه إلى الاهتمام بتوفير خدمات وتسهيلات وتجهيزات وعناصر جذب مختلفة داخل محافظة الطائف التي تعتبر من أهم مقومات الجذب السياحي. جاءت العبارة رقم (^) وهي" خدمات المركز الصحي" بالمرتبة الرابعة من حيث موافقة أفراد الدراسة بدرجة جيد وبمتوسط (10 ـب)، ونتير هذه النتيجة إلى أن ما نسبته (T7\%) من أفراد عينة الدراسة موافقين بدرجة تشير إلى جيد، وتفسر تلك النتيجة أهمية توفر الخدمات الصحية سواء كان مركز صحي أو مستشفى بالقرب من المواقع السياحية لتوفير الخدمات الصحية. جاءت العبارة رقم (V) وهي" نظافة المرافق العامة" بالمرتبة الخامسة من حيث موافقة أفراد عينة الدراسة عليها بدرجة جيد بمتوسط (ب)، وتشير هذه النتيجة إلى أن ما نسبته

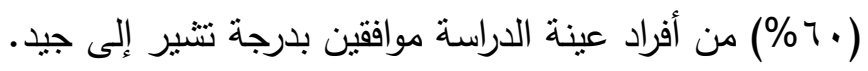

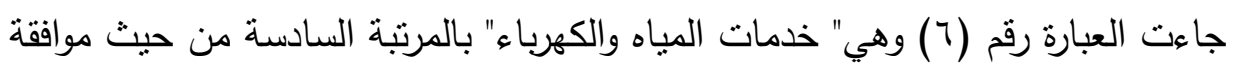

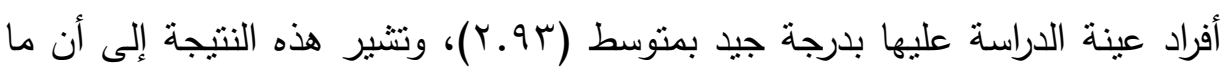

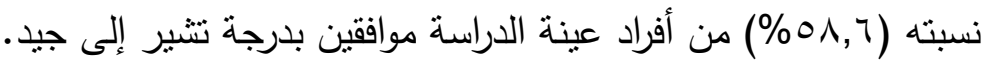


• جاءت العبارة رقم (0) وهي" تعامل المجتمع المحلي" بالمرتبة السابعة من حيث موافقة

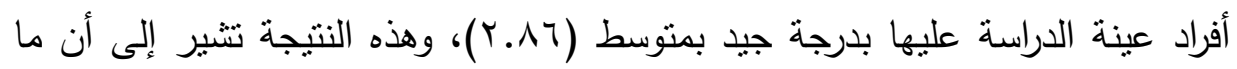
نسبته (r.Y.Y. من أفراد عينة الدراسة موافقين بدرجة تشير إلى جيد.

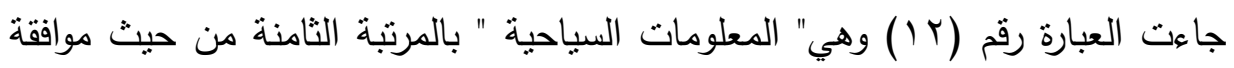
أفراد الدراسة عليها بدرجة جيد بمتوسط (Y.M.Y)، وهذه النتيجة تشير إلى أن ما نسبته

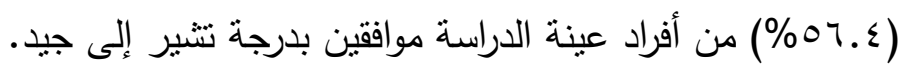

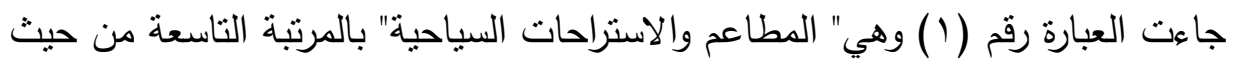

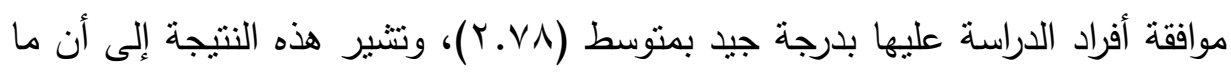
نسبته (40.7\%) من أفراد عينة الدراسة موافقين بدرجة نتير إلى جيد. أما عبارة (ع) وهي "خدمات مركز الزوار" جاءت في المرتبة العاثرة من حيث موافقة

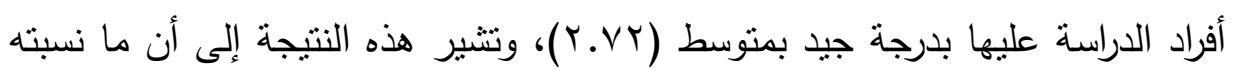

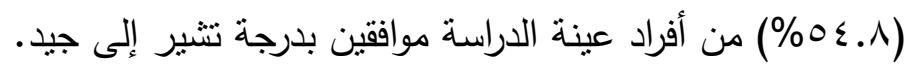

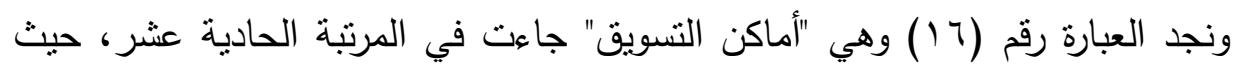

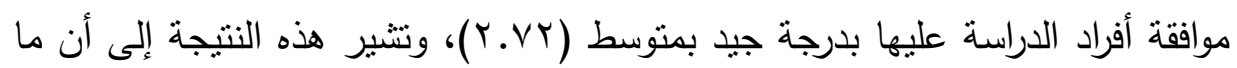

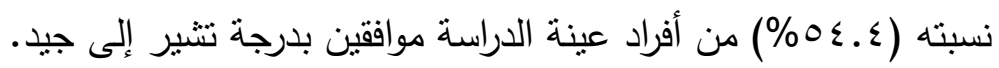

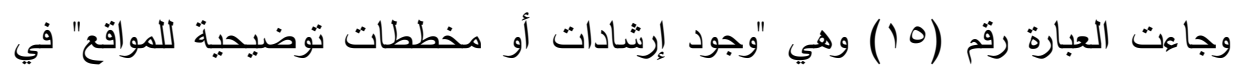

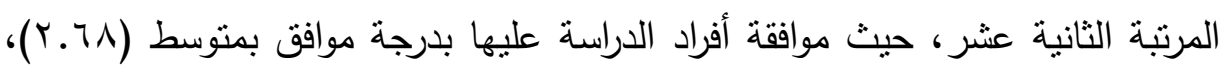
وتثير هذه النتيجة إلى أن ما نسبته (T.ب\%\%) من أفراد عينة الدراسة موافقين بدرجة تشير إلى جيد على أهمية وجود إرشادات أو مخططات توضيحية للمواقع. وفيما يتعلق بالعبارة رقم (Y) وهي "مراكز الاستعلامات السياحية" جاءت في المرتبة

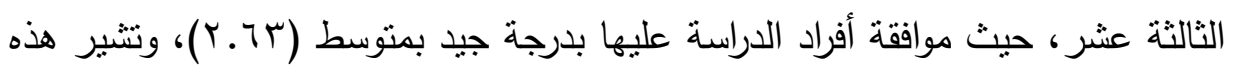

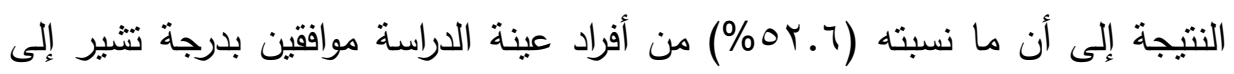
جيد.

ونجد العبارة رقم (ץ) وهي "الطرق والمواصلات" جاءت في المرنبة الرابعة عشر، حيث

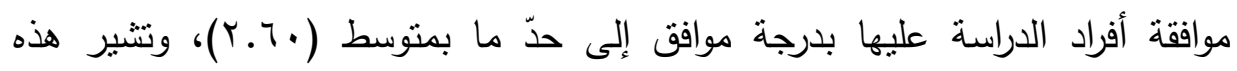




\section{مقومات الجذب السياحي في مدينة الطائف}

النتيجة إلى أن ما نسبته (\%०\%) من أفراد عينة الدراسة موافقين إلى بدرجة منوسط فئة

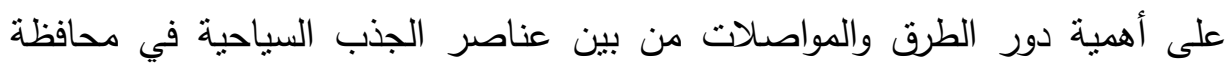
الطائف.

وجاءت العبارة رقم (ع () وهي "خدمات البنوك والصرافة" في المرتبة قبل الأخيرة، حيث

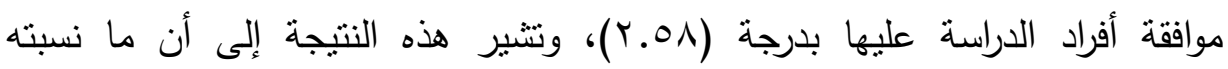

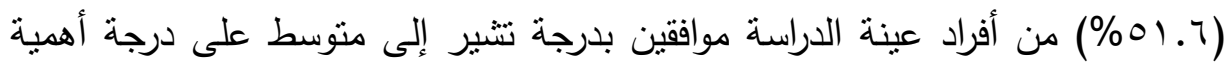
خدمات البنوك والصرافة من بين عناصر الجذب السياحية في محافظة الطائف.

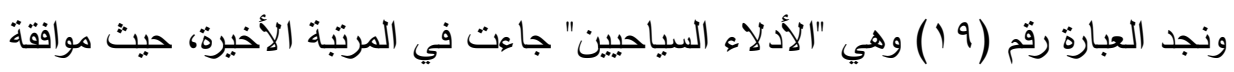

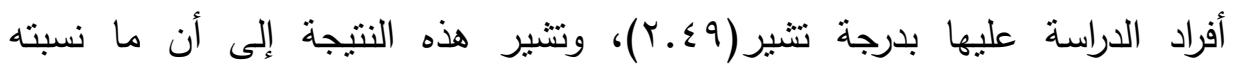

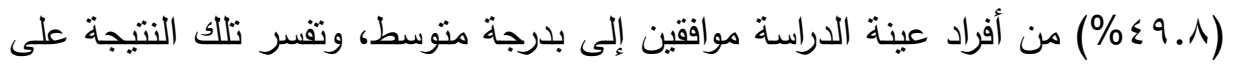

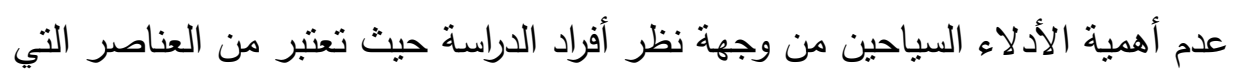

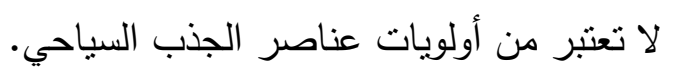

جدول (r) توزيع إجابات عينة الاراسة على عناصر الجذب السياحي بمدينة الطائف

\begin{tabular}{|c|c|c|c|c|c|c|c|c|c|c|c|}
\hline الترتيب & لدرجة افقة & الانحراف & الحستوسي & ضعيف & متوسط & جيا & عالي & جالي & & العبارة & الرقم \\
\hline \multirow{2}{*}{1} & \multirow[b]{2}{*}{ عالي } & \multirow{2}{*}{1.1} & \multirow{2}{*}{$\leqslant .10$} & 7 & 09 & 70 & $\leqslant Y$ & Y4 & $ت$ & الأمن & \multirow{2}{*}{1.} \\
\hline & & & & $1, \mathfrak{s}$ & 14 & 10,1 & $9, \wedge$ & $7 \cdot, \mathrm{V}$ & $\%$ & والاستقرار & \\
\hline \multirow{2}{*}{ Y } & \multirow{2}{*}{ عالي } & \multirow{2}{*}{1.1} & \multirow{2}{*}{$r .09$} & 9 & 71 & $11 \mathrm{~V}$ & Irr & $1 \cdot \varepsilon$ & $ت$ & \multirow{2}{*}{ وسيائل الترفيه } & \multirow{2}{*}{9} \\
\hline & & & & $r, 1$ & 10,1 & $r v, r$ & $r \cdot, v$ & $r \leqslant, r$ & $\%$ & & \\
\hline \multirow{2}{*}{$r$} & \multirow{2}{*}{ جيا } & \multirow{2}{*}{$1 . .1$} & \multirow{2}{*}{ r.YV } & 9 & $\leqslant 0$ & YYY & IrT & YV & ت & \multirow{2}{*}{ الأنشيطة } & \multirow{2}{*}{11} \\
\hline & & & & $r, 1$ & $1 \cdot, 0$ & or, 1 & $r \wedge, \uparrow$ & $7, r$ & $\%$ & & \\
\hline \multirow{2}{*}{$\varepsilon$} & \multirow{2}{*}{ جيد } & \multirow{2}{*}{$\cdot .^{\wedge}$} & \multirow{2}{*}{ r.10 } & 1. & Vo & $r . q$ & 119 & r. & ت & \multirow{2}{*}{ خلصمات المركز } & \multirow{2}{*}{$\Lambda$} \\
\hline & & & & $r, r$ & $1 V, \varepsilon$ & $\varepsilon V, q$ & $r V, V$ & $\varepsilon, V$ & $\%$ & & \\
\hline \multirow{2}{*}{0} & \multirow{2}{*}{ جيا } & \multirow{2}{*}{$\cdot .^{\wedge} \varepsilon$} & \multirow{2}{*}{$r$} & 1. & $1 \ldots$ & $r \cdot r$ & $11 \mathrm{~V}$ & 1 & ت & \multirow{2}{*}{ نظافة المرافق } & \multirow{2}{*}{ V } \\
\hline & & & & $r, r$ & rr, & $\leqslant V$ & $r V, r$ & $\cdot, r$ & $\%$ & & \\
\hline \multirow{2}{*}{7} & \multirow{2}{*}{ جيا } & \multirow{2}{*}{$\cdot . \vee \wedge$} & \multirow{2}{*}{ r.9r } & $\wedge$ & 1.0 & rrq & $\Lambda \varepsilon$ & $\varepsilon$ & $ت$ & خدمات المياه & 7 \\
\hline & & & & 1,9 & $Y \leqslant, \leqslant$ & or,r & 19,0 & $\cdot, 9$ & $\%$ & والكهرباء & 1 \\
\hline$y$ & & . $y \leqslant$ & ror & $\varepsilon$ & $11 \leq$ & YOY & ov & $r$ & $ت$ & تعامل المجتمع & 0 \\
\hline & جيز & $\because v=$ & T.A & $\cdot, 9$ & $r 7,0$ & $0 \wedge, 7$ & $1 \pi, r$ & $\cdot, \mathrm{V}$ & $\%$ & المحلي & \\
\hline$\Lambda$ & 11 & 17 & YAr & 7 & 11. & YVO & rY & V & ت & المعلومات & $1 \%$ \\
\hline$n$ & جيخ & 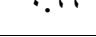 & 1.01 & 1,8 & ro, 7 & $7 \leq$ & $v, q$ & 1,7 & $\%$ & السياحية & 11 \\
\hline & & & & $r q$ & 94 & $r \leq Y$ & $\leq \leqslant$ & Ir & $ت$ & المطاعم & \\
\hline 9 & جيذ & צ & 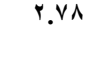 & $\wedge, \varepsilon$ & $r^{1}, \underline{4}$ & ov,r & $1 \cdot, r$ & $r, \wedge$ & $\%$ & والاسيتراحية & 1 \\
\hline 1. & 14 & $\cdot \hat{0}$, & $y=$ & $\varepsilon$ & $1 \leq 7$ & YrV & $\leqslant Y$ & 1 & ت & خدمات مركز & $\xi$ \\
\hline 10 & بي & 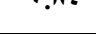 & 1.06 & $\cdot, 9$ & $r \leq$ & 00,1 & 9,1 & $\cdot, r$ & $\%$ & الزوار & \\
\hline
\end{tabular}


تابع جدول (r) توزيع إجابات عينة الدراسة على عناصر الجذب السياحي بمدينة الطائف

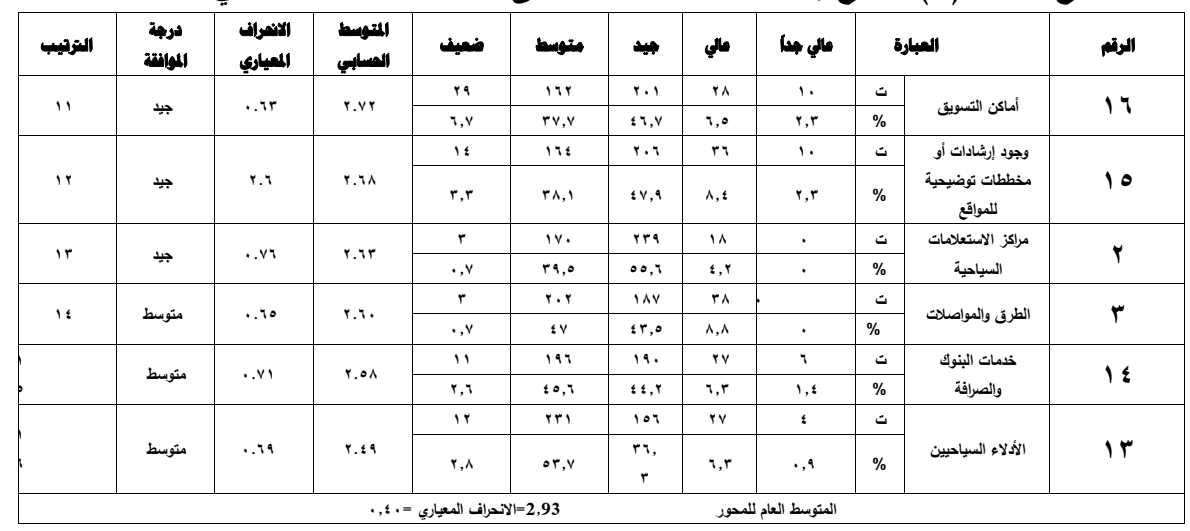

المصدر: الجدول من إعداد الطالب من خلال تحليل بيانات استمارة الاستيان 


\section{توصيات الدراسة:}

من خلال النتائج التي نم التوصل إليها يوصي الباحث بما يلي:

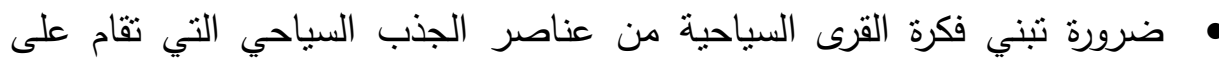

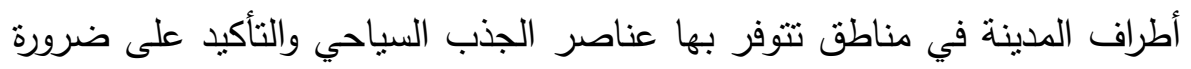
ملاءمة أسعارها لجميع الفئات.

• التأكيد على أهية التتسيق لإعداد برامج سياحية منظمة بالتعاون مع الفنادق والثقق الفندقية ووكالات السفر والسياحة والثركات السياحية لزيارة المناطق الأثرية

والتزاثية.

• تدعيم شبكة النقل والمواصلات في الدينة لتسهيل نقل وحركة السكان والسياح

$$
\text { بيسر وسهولة. }
$$

• الحفاظ على مستوى الخدمات المقدمة في المنشآت السياحية بإلزام المتعاقدين

بالتطور المستمر لهذه المنشآت وصيانتها.

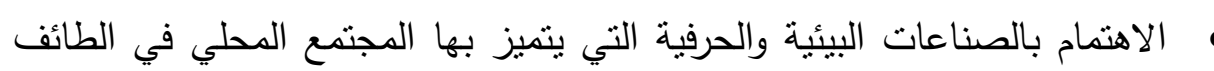

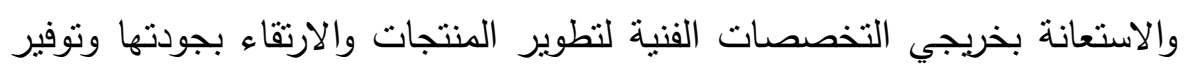

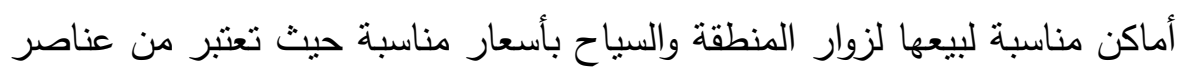

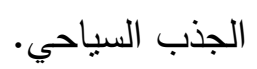




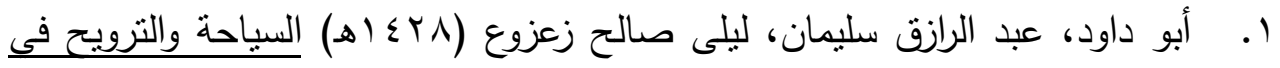
جدة، الدفاهيم والسياسات والموارد. جدة .

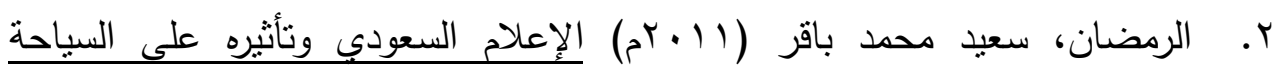
الألية رسالة ماجستير في الإعلام والاتصال، رسالة ماجستير، كلية الآداب التربية. الأكاديمية العربية المفتوحة في الدنمارك.

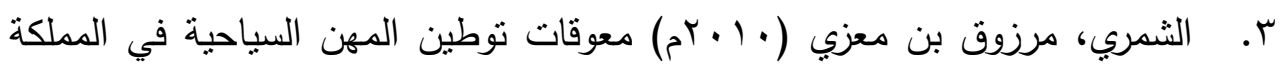

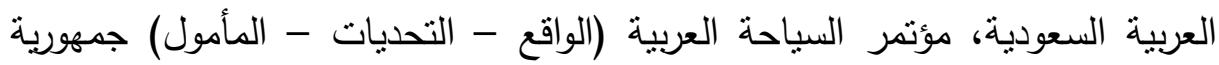

$$
\text { مصر العربية. }
$$

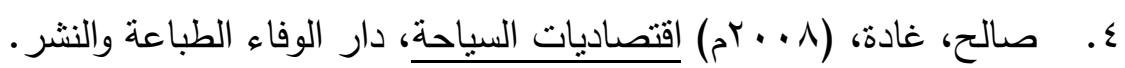

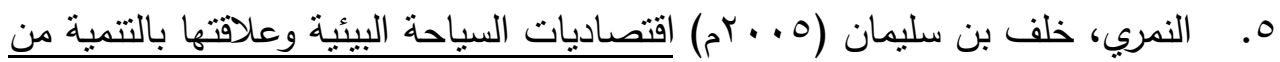
منضور إسلامى مع الإثارة لتتمية السياحة البيئية في المملكة العربية السعودية،

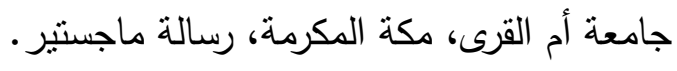

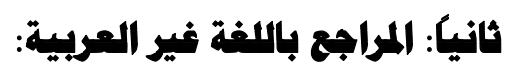

1. Bordelais 'Jean philippe V" : Environmental policy development in the Caribbean, Barbados, the Dominican Republic, and Guadeloupe", $\mathrm{Ph}$. D., George Mason University, 2007.

2. Fennell, D.A. \& Ebert, K "Tourism and the Precautionary Principle". Journal of Sustainable Tourism 12(6), 2004. 
مقومات الجذب السياحي في مدينة الطائف

The Elements of Tourism attractions in Taif City 